\title{
The value of lipoprotein(a) as a risk factor and its association with major risk factors in high and low-risk dyslipidemic patients according to Framingham risk scoring system
}

\section{Framingham risk skorlama sistemine göre düşük ve yüksek riskli dislipidemik hastalarda lipoprotein(A)'nın risk faktörü olarak değeri ve majör risk faktörleriyle ilişkisi}

Betül EKIz BíLiR ${ }^{1}$, Bülent BíLíR², Mümtaz TAKIR ${ }^{3}$

\section{ABSTRACT}

The aim of our study was to evaluate lipoprotein(a) whose plasma levels are mostly under genetic regulation as a risk factor for coronary artery disease in Turkish dyslipidemic patients according to Framingham risk scoring system. Totally 173 high and low-risk dyslipidemic patients according to Framingham risk scoring system were enrolled and association of $L p(a)$ with major risk factors were studied. At the end of the study, there was not a statistically significant correlation between the $L p(a)$ level and Framingham risk group. Although there was a statistically significant positive correlation between TG levels and high levels of $L p(a)$, there were not such a relationship between high levels of $L p(a)$ and other parameters such as age, sex, HT, DM, smoking status, total cholesterol, HDL cholesterol and LDL cholesterol.

Key words: Lipoprotein(a), Dyslipidemia, Framingham risk scoring system
Öz

Bu çalışmadaki amacımız, plazma seviyeleri çoğunlukla genetik regülasyon altında olan Lipoprotein $(a)[L p(a)]$ 'in, Türk dislipidemik hastalarda koroner arter hastalığı için bir risk faktörü olarak kabul edilip edilemeyeceğini Framingham risk skorlama sistemine göre değerlendirmekti. Framingham risk skorlama sistemine göre düşük ve yüksek riskli 173 vaka çalışmaya alınmış ve Lp(a)'nın diğer majör risk faktörleriyle ilişkisine bakılmıştır. Çalışma sonucunda $L p(a)$ düzeyi ile Framingham risk grubu arasında istatistiksel olarak anlamlı bir ilişki saptayamadık. Lipoprotein(a) düzeyi ile trigliseridler arasında istatistiksel olarak anlamlı pozitif bir ilişki saptanmasına rağmen, cinsiyet, yaş, HT, DM varlığı, sigara kullanımı, total kolesterol, HDL kolesterol ve $L D L$ ile $L p(a)$ yüksekliği arasında anlamlı bir ilişki bulunamamıştır.

Anahtar kelimeler: Lipoprotein(a), Dislipidemi, Framingham risk skorlama sistemi

\section{Gíriş}

Koroner kalp hastalıkları (KKH), dünyada ve Türkiye'de mortalite sıralamasında birinci sıradadı ${ }^{1,2}$. Koroner kalp hastalığı ve inmeden oluşan kardiyovasküler hastalıklar (KVH)'dan birincil korunma önlemlerinin, hangi hastada, ne zaman başlatılması gerektiğine dair çalışmalar "risk faktörü" terimini ortaya çıkarmıştır. Değiştirilebilir ve değiştirilemez risk faktörleri belir- lenmiş ve değiştirilebilir risk faktörlerini ortadan kaldırabilmek için gerekli tedbirlerin vakit kaybetmeksizin alınması önerilmiştir. Framingham Kalp Çalışması bu risk faktörlerinin tanımında önemli rol almıştır ${ }^{3}$. Ancak bilinen klasik risk faktörlerine eklenebilecek yeni risk faktörleri için arayışlar sürmektedir .

Framingham skorlaması koroner kalp hastalığına ait klinik bulgusu olmayan kişilerdeki riski yansıtmakta-

Received: 09.02.2016

Accepted: 23.02 .2016

${ }^{1}$ Ministry of Health, Tekirdağ State Hospïtal, Endocrinnology and Metabolism Clinïc

${ }^{2}$ Namık Kemal Unıversıty School of Medicine, Department of Internal Medicine

${ }^{3}$ Minïstry of Health İstanbul Göztepe Education and Traïning Hospital, Endocrinology and Metabolism Clinïcs

Yazışma adresi: Betül Ekiz Bilir, Ministry of Health, Tekirdağ State Hospïtal, Endocrinology and Metabolism Cliniic, Tekirdağ

e-mail: bekiz99@yahoo.com.tr 
B. Ekiz Bilir et al., The value of lipoprotein(a) as a risk factor and its association with major risk factors in high and low-risk dyslipidemic patients according to Framingham risk scoring system

dır. Bu yüzden, skorlama yalnızca birincil korunmada geçerlidir. Herhangi bir risk faktörünün Framingham toplumundaki kesin değeri diğer tüm toplumlar için de aynı olmayabilir. NCEP-ATP III (National Cholesterol Education Program-Adult Treatment Panel III)'e göre düşük yoğunluklu lipoprotein (LDL) hedeflerinde etkin ana risk faktörleri şunlardır ${ }^{5}$ :

1. Yaş (erkeklerde $\geq 45$ yaş; kadınlarda $\geq 55$ yaş)

2. Sigara (son 1 ayda en az 1 sigara içmiş olmak)

3. Hipertansiyon (Arter kan basıncı $\geq 140 / 90 \mathrm{mmHg}$ veya antihipertansif ilaç kullanıyor olmak)

4. Düşük HDL (yüksek yoğunluklu lipoprotein) düzeyi (<40 mg/dl) (HDL kolesterolün $\geq 60 \mathrm{mg} / \mathrm{dl}$ olması negatif bir risk faktörü olarak değerlendirilir.)

5. Ailede erken yaşta KKH öyküsü olması (Birinci derece akrabalardan 55 yaş altı erkek ve 65 yaş altı kadınlarda KKH olması)

Güncellenmiş NCEP-ATP III kılavuzu, koroner ölüm veya ölümcül olmayan Ml'dan oluşan majör koroner olayların hesaplanan 10 yıllık riskine bağlı olarak "Yüksek, orta-yüksek, orta-düşük ve düşük" olmak üzere 4 risk kategorisi tanımlar.

Lp(a), LDL'nin çevresinde yerleşmiş Apo-B100'e bir disülfid bağıla bağlanan glikoprotein yapıda, plazminojenle ciddi bir aminoasit sıralanma homolojisine sahip apolipoprotein(a) [Apo(a)]'dan oluşmaktadır $^{6}$. Bu yapısal benzerlik nedeniyle, endotelyal hücre yüzeyine ve fibrine bağlanmada plazminojenle yarıştığı ve böylece fibrin yıkımını engellediği düşünülmektedir.

Lipoprotein(a) lipid transportu ve pıhtılaşma sistemi gibi iki önemli alanda görev yapmaktadır. İşte bu yüzden, Lp(a)'nın tromboz ve aterosklerozda rol alıp, dislipidemi ile koroner kalp hastalıkları (KKH) arasındaki bağlantıda etkin olduğu düşünülmüştür ${ }^{7}$. Lp(a) daha aterojenik proinflamatuvar okside fosfolipidleri taşımakta olup, inflamatuvar hücrelerin damar duvarına göçüne ve düz kas proliferasyonuna yol açar ${ }^{8-10}$. Hayvan çalışmaları Lp(a)'nın aterosklerotik hasara plak boyutunu, inflamasyonu, instabiliteyi ve düz kas hücre büyümesini arttırarak doğrudan katkı sağladığını ortaya koymuştur ${ }^{11}$.
Lp(a) serum düzeylerinin apo(a)'nın sentez hızına bağlı olup, büyük ölçüde apo(a) geni ile belirlendiği ve bu nedenle kalıtsal bir geçiş olduğu düşünülmektedir $^{12}$. Elektroforetik yöntemlerle ölçülen total $L p(a)$ $\geq 30 \mathrm{mg} / \mathrm{dl}$ değeri KKH için artmış riski temsil etmektedir. Total Lp(a)'nın $30 \mathrm{mg} / \mathrm{dl}$ ve üzeri olması, diğer risk faktörlerinin varlığına da bağlı olarak, KKH riskini 2-6 kat arttırmaktadır ${ }^{13-16}$.

Lp(a) konsantrasyonunun yaklaşık \%90'ı genetik düzenleme altındadır ${ }^{17}$. Akut faz yanıtı, kontrolsüz diyabet, karaciğer yetersizliği, böbrek ve LDL reseptör genindeki defektlerin bu lipoproteinin metabolizmasını etkilediği bilinmektedir ${ }^{18}$.

Plazmadaki Lp(a) konsantrasyonu yaşla birlikte hafifçe artar ve siyahlarda beyazlara göre yüksektir ${ }^{19}$. Lp(a) düzeyi diğer lipoproteinlerden farklı olarak kilo, yaş, cinsiyet, diyet, kilo kaybı, egzersiz gibi yaşam tarzı değişikliklerinden ve sigara kullanımından daha az etkilenir $^{20}$. Lp(a)'nın MI ve inme sonrasında da serum düzeylerinin arttığı bildirilmiştir ${ }^{21}$.

Ülkemizin de içinde bulunduğu 2010'da yayınlanan çok merkezli Avrupa Ateroskleroz Birliği konsensus raporunda erken $\mathrm{KVH}$ geçiren, ailesel hiperkolesterolemisi, ailesinde erken KVH öyküsü, ailesinde yüksek Lp(a) öyküsü olan ve statin tedavisine rağmen, yineleyen $\mathrm{KVH}$ geçiren hastalarla, Avrupa kılavuzlarına göre 10 yıllık ölümcül KVH riski \%3'ten, Amerika kılavuzlarına göre 10 yıllık ölümcül olan veya olmayan $\mathrm{KKH}$ riski \%10'dan fazla olan orta veya yüksek KVH/KKH risk altındaki vakalar Lp(a) düzeyleri açısından taranmalıdır. Bunlardan $50 \mathrm{mg} / \mathrm{dl}$ (beyaz ırkta 80. persantile denk gelen düzey) üzeri vakalar tedavi edilmelidir ${ }^{22}$.

Bu çalışmanın amacı, Framingham Risk Skorlama Sistemi'ne göre yüksek ve düşük riskli oldukları saptanan Türk vakalardaki Lp(a) kan düzeylerine bakarak, Türkiye'de bir risk faktörü olarak değerlendirilip değerlendirilemeyeceğini ve majör risk faktörleriyle arasındaki ilişkiyi araştırmaktır. 


\section{GEREÇ ve YÖNTEM}

Bu çalışma hastanemiz yerel etik kurulunca onanmış olup, hastalardan Helsinki Bildirgesi doğrultusunda bilgilendirilmiş onamları alınmıştır.

Ekim 2005-Şubat 2006 tarihleri arasında T.C. SağIık Bakanlığı İstanbul Göztepe Eğitim ve Araştırma Hastanesi Merdivenköy iç Hastalıkları polikliniklerine başvuran uygun vakaların 12 saatlik açlıkta lipid profilleri çalışılmıştır. Vakalardan nefrotik sendrom, kontrolsüz hipotiroidizm, karaciğer yetersizliği, hepatobiliyer hastalık, böbrek yetersizliği, geçirilmiş KVH öyküsü olan ve glukokortikoid, oral kontraseptif/ hormon replasman tedavisi, lipid düşürücü tedavi ve bağımlılık düzeyinde alkol kullananlar çalışma dışı bırakılmıştır.

Yaş, hipertansiyon, aile öyküsü, sigara içimi sorgulanarak ve HDL düzeyleri göz önüne alınarak NCEP-ATP III'e göre dislipidemik olduğu saptanan vakaların 10 yıllık KKH riski Framingham Risk Skorlama Sistemi'ne göre hesaplanmıştır ${ }^{5}$ 0-1 majör risk faktörü taşıyan vakalar "düşük riskli"; 2 ve üzeri majör risk faktörü taşıyan vakalardan, hesaplanan Framingham Risk Skoru \% 20 üzeri bulunanlarla tüm diyabetik hastalar "yüksek riskli" olarak kabul edilmiş ve çalışmaya alınmıştır²3. Framingham Risk Skoru \%10-20 olan "ortayüksek risk"li vakalar çalışma dışı bırakılmıştır.

Lipoprotein(a) düzeyleri Marmara Üniversitesi Merkez Laboratuvarındaki Dade Behring cihazı ile ölçülmüştür. Tam heparinize plazma veya serum santrifüje edildikten sonra, BN Prospec serum kullanılarak partikülle-güçlendirilmiş immünonefelometrik yöntemle değerlendirme yapılarak sonuçlar mg/ dl olarak verilmiştir. Trigliserid, total kolesterol, HDL ölçümleri 5200 AU Olympus marka otoanalizörde fotometrik olarak, T.C. S.B. Göztepe Eğitim ve Araştırma Hastanesi Merdivenköy Poliklinikleri Biyokimya Laboratuvarında yapılmış ve sonuçları $\mathrm{mg} / \mathrm{dl}$ olarak verilmiştir. LDL değerleri ise Friedewald formülü ile hesaplanmıştır ${ }^{24}$.

\section{İstatistiksel İncelemeler:}

Çalışmada elde edilen bulguların istatistiksel analizlerinde "SPSS (Statistical Package for Social Sciences) for Windows 10.0" programı kullanıldı. Çalışma verileri değerlendirilirken tanımlayıcı istatistiksel metodlara (Ortalama, Standart sapma) ek olarak niceliksel verilerin karşılaştırılmasında Student t testi; niteliksel verilerin karşılaştırılmasında ise ki-kare testi ve Fisher's Exact ki-kare testi kullanıldı. Parametreler arasındaki ilişkiler Pearson korelasyon testi ile değerlendirildi. Sonuçlar \%95'lik güven aralığında, anlamlılık ise $p<0.05$ düzeyinde değerlendirildi.

\section{BULGULAR}

Framingham Risk Skorlama Sistemine göre düşük (62 kadın, 8 erkek toplam 70 vaka) veya yüksek (59 kadın, 44 erkek toplam 103 vaka) risk grubuna giren yaşları 31-80 arasında değişen, yaş ortalaması 54,03 $( \pm 9,07)$ olan 121 kadın ve 52 erkek (toplam 173 vaka) çalışmaya dâhil edilmiştir. Risk faktörlerinin cinsiyete göre

Tablo 1. Risk faktörlerinin cinsiyete göre dağılımı.

\begin{tabular}{|c|c|c|c|c|c|c|}
\hline \multicolumn{7}{|l|}{ Risk faktörü } \\
\hline \multirow[t]{2}{*}{$\begin{array}{l}\text { Cinsiyet } \\
\text { Yaş ortalaması }( \pm S D)\end{array}$} & \multicolumn{2}{|c|}{$\begin{array}{c}\text { Kadın } \\
52,84 \\
( \pm 8,54)\end{array}$} & \multicolumn{2}{|c|}{$\begin{array}{c}\text { Erkek } \\
56,79 \\
( \pm 9,72)\end{array}$} & \multicolumn{2}{|c|}{$\begin{array}{c}\text { Total (sayı) } \\
54,03 \\
( \pm 9,07)\end{array}$} \\
\hline & Sayı & $\%$ & Sayı & $\%$ & Sayı & $\%$ \\
\hline & 121 & 69,9 & 52 & 30,1 & & 173 \\
\hline \multicolumn{7}{|l|}{ Sigara } \\
\hline İçenler & 24 & 19,8 & 17 & 32,6 & 41 & 23,7 \\
\hline İçmeyenler & 97 & 80,1 & 35 & 67,3 & 132 & 76,3 \\
\hline \multicolumn{7}{|l|}{ Hipertansiyon } \\
\hline Yok & 72 & 59,5 & 23 & 44,2 & 95 & 54,9 \\
\hline Var & 49 & 40,5 & 29 & 55,8 & 78 & 45,1 \\
\hline \multicolumn{7}{|l|}{ Aile öyküsü } \\
\hline Yok & 106 & 87,6 & 43 & 82,7 & 149 & 86,1 \\
\hline Var & 15 & 12,4 & 9 & 17,3 & 24 & 13,9 \\
\hline \multicolumn{7}{|l|}{ Diyabetes mellitus } \\
\hline Yok & 70 & 57,9 & 25 & 48,1 & 95 & 54,9 \\
\hline Var & 51 & 42,1 & 27 & 51,9 & 78 & 45,1 \\
\hline \multicolumn{7}{|l|}{ Risk faktörü olarak HDL } \\
\hline $\mathrm{HDL} \geq 60 \mathrm{mg} / \mathrm{dl}$ & 30 & 24,8 & 7 & 13,5 & 37 & 21,4 \\
\hline $40 \leq \mathrm{HDL}<60 \mathrm{mg} / \mathrm{dl}$ & 73 & 60,3 & 27 & 51,9 & 100 & 57,8 \\
\hline $\mathrm{HDL}<40 \mathrm{mg} / \mathrm{dl}$ & 18 & 14,9 & 18 & 34,6 & 36 & 20,8 \\
\hline
\end{tabular}


dağılımı Tablo 1'de belirtilmiştir. Lp(a)'nın diğer risk faktörleri ile ilişkisi Tablo 2 ve 3'te verilmiştir.

Tablo 2. Lipoprotein(a) düzeyi ile yaş ve lipidlerin ilişkisi.

\begin{tabular}{lll}
\hline & \multicolumn{2}{c}{ Lp(a) } \\
\cline { 2 - 3 } & \multicolumn{1}{c}{$\mathbf{p}$} & $\mathbf{p}$ \\
\hline Yaş & 0,109 & 0,152 \\
Trigliserit & 0,149 & $0,050^{*}$ \\
Total Kolesterol & $-0,019$ & 0,809 \\
HDL & $-0,146$ & 0,055 \\
LDL & $-0,020$ & 0,796 \\
\hline
\end{tabular}

r: Pearson korelasyon testi

Lipoprotein(a) düzeyi ile cinsiyet arasında istatistiksel olarak anlamlı bir ilişki bulunmamaktadır ( $p>0.05$ ). Kadın vakalarda Lp(a) düzeyinin 30 ve üzerinde olma oranı $\% 28,1$ iken, erkek vakalarda bu oran \% 40,4'tür ( $p>0,05)$.

Lipoprotein(a) düzeyi ile yaş, total kolesterol ve LDLkolesterol düzeyleri arasında istatistiksel olarak anlamlı bir ilişki bulunmamaktadır $(p>0,05)$.

Lipoprotein(a) düzeyi ile HDL düzeyi arasında negatif yönde; $\% 14,6$ düzeyinde bir korelasyon olup, bu ilişki anlamlılığa yakın olmakla birlikte, istatistiksel olarak anlamlı bulunmamıştır ( $p>0,05)$.

Lipoprotein(a) düzeyi ile trigliserid düzeyi arasında pozitif yönde; \%14,9 düzeyinde ve istatistiksel olarak anlamlı bir korelasyon bulunmaktadır $(p=0,05)$.
Lipoprotein(a) düzeyi ile Framingham risk grubu arasında istatistiksel olarak anlamlı bir ilişki bulunmamaktadır $(p>0,05)$. Düşük risk grubundaki vakalarda $\mathrm{Lp}(\mathrm{a})$ düzeyinin 30 ve üzerinde olma oranı \% 30 iken, yüksek risk grubundaki vakalarda bu oran \%33'tür.

Lipoprotein(a) düzeyi ile risk faktörü olarak yaşın arasında istatistiksel olarak anlamlı bir ilişki bulunmamaktadır $(p>0,05)$. Bununla birlikte 55 yaş ve üzeri kadın vakalar ile 45 yaş ve üzeri erkek vakalarda Lp(a) düzeyinin 30 ve üzerinde olma oranının $(\% 36,3), 55$ yaş altı kadın vakalar ile 45 yaş altı erkek vakalarda $L p(a)$ düzeyinin 30 ve üzerinde olma oranından $(\% 26,8)$ daha yüksek oluşu dikkat çekicidir.

Lipoprotein(a) düzeyi ile risk faktörü olarak HDL düzeyi arasında istatistiksel olarak anlamlı bir ilişki bulunmaktadır $(p<0,05)$. HDL düzeyi 40'ın altında olan vakalardaki $L p(a)$ düzeyinin 30 ve üzerinde olma oranı $(\% 50), H D L$ düzeyi 60 ve üzerinde $(\% 35,1)$ ve 40 ile 60'ın altı arasında (\%24) olan vakalardaki Lp(a) düzeyinin 30 ve üzerinde olma oranlarından anlamlı düzeyde yüksek bulunmuştur.

Lipoprotein(a) düzeyi ile sigara kullanımı, diyabet durumu, aile öyküsü arasında istatistiksel olarak anlamIı bir ilişki bulunmamaktadır (tüm p'ler >0,05). Lp(a) düzeyinin 30 ve üzerinde olma oranı sigara kullanan-

Tablo 3. Risk faktörlerine göre Lipoprotein(a) değerlendirilmesi.

\begin{tabular}{|c|c|c|c|c|c|c|}
\hline & & \multicolumn{4}{|c|}{ Lipoprotein(a) } & \multirow[b]{3}{*}{ Test ist.; $p$} \\
\hline & & \multicolumn{2}{|c|}{$<30 \mathrm{mg} / \mathrm{dl}$} & \multicolumn{2}{|c|}{$\geq 30 \mathrm{mg} / \mathrm{dl}$} & \\
\hline & & $\mathrm{n}$ & $\%$ & $\mathrm{n}$ & $\%$ & \\
\hline \multirow{2}{*}{ Framingham Risk Grubu } & Düşük Risk & 49 & 70,0 & 21 & 30,0 & \multirow{2}{*}{$\chi 2: 0,174$ p:0,676 } \\
\hline & Yüksek Risk & 69 & 67,0 & 34 & 33,0 & \\
\hline \multirow[t]{2}{*}{ Risk Faktörü Olarak Yaş } & $\mathrm{K}<55, \mathrm{E}<45$ & 60 & 73,2 & 22 & 26,8 & \multirow[t]{2}{*}{$\chi 2: 1,770 \mathrm{p}: 0,183$} \\
\hline & $K \geq 55, E \geq 45$ & 58 & 63,7 & 33 & 36,3 & \\
\hline \multirow[t]{3}{*}{ Risk Faktörü Olarak HDL (mg/dl) } & $\mathrm{HDL} \geq 60$ & 24 & 64,9 & 13 & 35,1 & \multirow[t]{3}{*}{$\chi 2: 8,495 \mathrm{p}: 0,014^{*}$} \\
\hline & $40 \leq \mathrm{HDL}<60$ & 76 & 76,0 & 24 & 24,0 & \\
\hline & $\mathrm{HDL}<40$ & 18 & 50,0 & 18 & 50,0 & \\
\hline \multirow[t]{2}{*}{ Sigara } & Var & 32 & 78,0 & 9 & 22,0 & \multirow[t]{2}{*}{$\chi 2: 0,174 p: 0,676$} \\
\hline & Yok & 86 & 65,2 & 46 & 34,8 & \\
\hline \multirow[t]{2}{*}{ Diyabet } & Var & 54 & 69,2 & 24 & 30,8 & \multirow[t]{2}{*}{$\chi 2: 0,069 \mathrm{p}: 0,794$} \\
\hline & Yok & 64 & 67,4 & 31 & 32,6 & \\
\hline \multirow[t]{2}{*}{ Hipertansiyon } & Var & 48 & 61,5 & 30 & 38,5 & \multirow[t]{2}{*}{$\chi 2: 2,914 p: 0,088$} \\
\hline & Yok & 70 & 73,7 & 25 & 26,3 & \\
\hline \multirow{2}{*}{ Aile Hikayesi } & Var & 17 & 70,8 & 7 & 29,2 & \multirow{2}{*}{$\chi 2: 0,089 p: 0,766$} \\
\hline & Yok & 101 & 67,8 & 48 & 32,2 & \\
\hline
\end{tabular}

$\chi^{2}$ : Ki-kare testi, ${ }^{*} p<0.05$ düzeyinde anlamlı 
larda \%22, kullanmayanlarda \%34,8, diyabetli vakalarda $\% 30,8$, diyabeti olmayan vakalarda $\% 32,6$, aile öyküsü olanlarda $\% 29,2$, olmayanlarda ise $\% 32,2$ 'dir.

Lipoprotein(a) düzeyi ile hipertansiyon varlığı arasında anlamlılığa yakın olmakla birlikte, istatistiksel olarak anlamlı bir ilişki bulunmamaktadır $(p>0,05)$. Öyle ki hipertansiyonu olan vakalarda Lp(a) düzeyinin 30 ve üzerinde olma oranının $(\% 38,5)$; hipertansiyonu olmayan vakalarda $L p(a)$ düzeyinin 30 ve üzerinde olma oranından $(\% 26,3)$ daha yüksek oluşu dikkat çekicidir.

\section{TARTIŞMA}

Biz bu çalışmada, Lp(a)'nın klinik etkinliği ispatlanmış bir risk skorlama sistemi olan Framingham Risk Skorlama Sistemi'ne göre yüksek ve düşük riskli oldukları hesaplanan vakalardaki düzeylerine bakarak Türkiye'de bir risk faktörü olarak değerlendirilebilirliğini ve majör risk faktörleriyle arasındaki ilişkiyi araştırmak istedik.

Lp(a) ile ateroskleroz ilişkisi birçok çalışmada araştırılmış ve $\mathrm{MI}$ ile KKH'a bağlı ölüm için risk oluşturduğu gösterilmiştir. Ancak prospektif çalışmaların sonuçları çelişkilidir. Prospektif "Iceland çalışması"na göre yüksek Lp(a) seviyelerinin MI gelişimi için bağımsız bir risk faktörü olduğu belirtilmiş, ancak bir diğer prospektif çalışma olan ve orta yaşlı erkeklerle yapılan "Helsinki Heart Study" sonuçları bu bulguyu desteklememiştir ${ }^{25}$.

Nascetti ve ark.'nca ${ }^{26}$ yayınlanan 1319 vakalık "Brisighella Çalışması", Lp(a) ile KVH ve diğer risk faktörlerinin ilişkisini araştırmıştır. Bu çalışmanın sonucunda, $\mathrm{Lp}(\mathrm{a})$ seviyelerinde, her iki cinsiyet için de $\mathrm{KVH}$ ve kontrol grubunda, $H T$, obezite ve DM gibi diğer risk faktörleri göz önüne alındığında bile, istatistiksel olarak anlamlı bir fark saptanmamıştır. Araştırıcılar buldukları sonuçlardan yola çıkarak, Lp(a)'nın KVH için bağımsız ve prediktif bir risk faktörü olarak kabul edilemeyeceği yorumunda bulunmuşlardır.

Lp(a) ile KKH ilişkisini inceleyen ve 10 yıl ortalama izlem süresi olan, prospektif 27 çalışmanın metaanalizinde, katılımcılar bazal $L p(a)$ değerlerine göre üç gruba ayrılmışlardır. Populasyon bazlı 18 çalışmanın değerlendirilmesinde, en yüksek değerli grubun $\mathrm{KKH}$ riskinin, en alt değerli gruba göre \%70 fazla olduğu görülmüştür. Bununla birlikte, klasik vasküler risk faktörleri ile plazma $L p(a)$ arasında kuvvetli bir korelasyon bulunmamıştır ${ }^{27}$.

Günümüzde yeni bir kardiyovasküler risk faktörü kabul edilen Lp(a) ile ilgili 2009'da yayınlanan, üç büyük çalışmanın katılımcılarının değerlendirildiği bir çalışmada ise artmış Lp(a) ile artmış MI riski arasında sebepsel bir ilişki olduğu ortaya konmuştur ${ }^{22,28}$. ATPIII kılavuzuna göre ise Lp(a) KVH için gün geçtikçe önem kazanan, lipid risk faktörlerindendir ${ }^{29}$. Mellwig ve ark.'nın ${ }^{30}$ bir raporunda, çok yüksek $L p(a)$ düzeylerinin $\mathrm{KKH}$ gelişimi ve ciddiyetini arttırdığı ortaya konmuştur. Yüz yirmi altı bin altı yüz otuz dört kişinin değerlendirildiği bir başka analizde ise $L p(a)$ değeri ile KKH arasında devamlı bir ilişki olduğu, bu ilişkinin diğer lipid fraksiyonları ve ispatlanmış risk faktörleri ile düzeltildikten sonra bile devam ettiği belirtilerek KKH için bağımsız bir risk faktörü olduğu öne sürülmüştür. Ancak Lp(a)'nın non-HDL kolesterolün öngörücü gücünün ancak $1 / 4$ 'ine sahip olduğu ve bu nedenle de orta güçte bir koroner risk faktörü olduğu belirtilmiştir ${ }^{31}$.

Framingham çalışmasında, Lp(a) yüksekliği yüksek $L D L$ veya düşük $H D L$ ile benzer oranlarda $K K H$ risk yükselmesine neden olmuşken, bu yükselmenin sigara kullanımı veya diyabetlilerde görülen risk artışından daha az olduğu gözlemlenmiştir ${ }^{14}$. ATP-III kılavuzu temel alındığında, Lp(a) KVH için gittikçe önem kazanan lipid risk faktörlerinden biridir ${ }^{29}$. NHLBI'nın bir raporunda, NCEP kılavuzlarına göre, Amerika'da KKH gelişimi açısından yüksek riskli bireylerin \%37'sinde serum Lp(a) düzeyleri yüksek iken, düşük riskli bireylerin ancak \%14'ünde Lp(a) düzeyleri yüksek hesaplanmış$\operatorname{tır}^{32}$. "Atherosclerosis Risk in Communities (ARIC)" çalışmasında diğer lipidlerden bağımsız istatistiksel anlamlılığı ortaya konmuş olsa da ölçüm maliyeti, diğer lipid risk faktörlerine Lp(a)'nın eklenmesinin KKH öngörüsüne getireceği ekstra kazancın henüz ciddi boyutlarda olmaması, doğrudan terapötik girişimin henüz var olmaması, yükselmiş Lp(a) düzeyinin teda- 
B. Ekiz Bilir et al., The value of lipoprotein(a) as a risk factor and its association with major risk factors in high and low-risk dyslipidemic patients according to Framingham risk scoring system

visinin ileride oluşacak kardiyovasküler olayları kesin azalttığına dair geçerli veri olmaması nedeniyle, Lp(a) ölçümünün klinikte kullanımının günümüz şartlarında iyice sorgulanması gerektiği bir gerçektir ${ }^{33}$.

Büyük bir meta-analizde, Lp(a) kitle ünitesi ile belirtilen Lp(a) konsantrasyonlarının çalışmalar arasında ciddi farklılıklar gösterdiği ve bu yüzden ölçüm standardizasyonunun gerekliliği ortaya konmuştur ${ }^{34}$. On dört prospektif çalışmanın 12'sinde başlangıç Lp(a) konsantrasyonlarının daha sonra KKH gelişen hastalarda gelişmeyenlere oranla daha yüksek olduğu ortaya çıkmış, ancak bu etkinin büyüklüğü çalışmalar arasında farklılık göstermiştir. Bu farklılığın örneklerin depolandığı ısının farklı olmasından kaynaklanabileceği ileri sürülmüştür.

Yüz yetmiş üç dislipidemik vaka ile yapılan bu çalışmada, cinsiyet, yaş, sigara kullanımı, DM, HT varlığı, total kolesterol ve LDL ile Lp(a) yüksekliği arasında anlamlı bir ilişki bulunamamıştır. Bulgularımızın ortaya çıkardığı Lp(a) düzeyi ile HDL düzeyleri arasında saptanan istatistiksel anlamlılığa kavuşmayan negatif yöndeki ilişki; $L p(a)$ düzeyi ve bir risk faktörü olarak HDL arasındaki istatistiksel anlamlı ilişki ile birleştirildiğinde klinik açıdan önem kazanabilir. Yalnızca dislipidemik vakaların alındığı çalışmamızda saptadığımız Lp(a) düzeyi ile trigliseridler arasındaki pozitif yöndeki ilişki, sağlıklı kişilerin de dâhil olduğu genel toplum bazlı daha büyük ölçekli bir çalışma ile desteklenmek gereksinimi doğurur.

Framingham Risk Skorlama Sistemine göre yüksek riskli vakaların, ileride $\mathrm{KVH}$ geçirme riski yüksek vakalar olduğu ve bu vakaların Lp(a) düzeylerinin yüksek olabileceği varsayımından yola çıkarak planladığımız bu çalışmada, risk grubu ile Lp(a) yüksekliği arasında anlamlı bir ilişki saptanmadı. Bunun bazı nedenleri olabilir. Birincisi, çalışmaya yalnızca dislipidemik vakaları alıp lipid profilleri normal kişileri çalışma dışı bıraktığımızdan, aterosklerotik süreci başlamış olma intimali zaten yüksek vakalarımızda Lp(a)'nın aterosklerotik gücü maskelenmiş olabilir. İkincisi, kullandığımız Lp(a) ölçüm metodu, total Lp(a) kitlesini ölçmekte olup apo(a) boyut heterojenitesini saptayamamakta- dır. Lp(a)'nın risk faktörü olarak değerlendirilemeyeceği sonucu çalışma kitimizin ateroskleroz açısından daha riskli olduğu bilinen küçük boyutlu apo(a)'nın oranını saptayamamasına bağlı olabilir. Allele veya izoforma özel kitlerin kullanımının Lp(a)'nın risk faktörü olarak değerlendirilmesinde özellikle erkeklerde daha tanımlayıcı olabileceği yapılan geniş ölçekli çalışmalarda zaten ortaya çıkmış bir gerçektir ${ }^{35,36}$. Üçüncüsü herhangi bir risk faktörünün Framingham toplumundaki mutlak riski, diğer tüm toplumlar için geçerli olmayabilir. Bu nedenle Türk toplumunda yaptığımız bu çalışmanın Framingham çalışması ile arasındaki uyumsuzluk zaten genetik kontrol altındaki bu belirtecin ırk farkına da bağlı olabilir.

Çalışmamızın vaka sayısı 173 ile sınırlı olduğundan sonuçlarımızın daha geniş sayılı, izoforma hassas yöntemlerle çalışılacak, daha büyük çalışmalarla teyit edilmesi gerekliliği göz ardı edilemez.

\section{KAYNAKLAR}

1. World Health Organization. Global status report on noncommunicable diseases 2010. Geneva: World Health Organization 2011 Contract No.: ISBN: 9789241564229.

2. Onat A, Murat SN, Çiçek $G$, et al. Regional distribution of allcause mortality and coronary disease incidence in Turkey: findings of Turkish Adult Risk Factor survey 2010. Türk Kardiyol Dern Ars 2011;39:263-8.

http://dx.doi.org/10.5543/tkda.2011.01446

3. Dawber TR, Meadors GF, Moore FE Jr. Epidemiological approaches to heart disease: the Framingham Study. Am J Public Health Nations Health 1951;41:279-81. http://dx.doi.org/10.2105/AJPH.41.3.279

4. Pahor M, Elam MB, Garisson RJ, et al. Emerging noninvasive biochemical measures to predict cardiovascular risk. Arch Intern Med 1999;159:237-45.

http://dx.doi.org/10.1001/archinte.159.3.237

5. National Cholesterol Education Program (NCEP) expert panel on detection, evaluation, and treatment of high blood cholesterol in adults (Adult Treatment Panel III). Third Report of the National Cholesterol Education Program (NCEP) expert panel on detection, evaluation and treatment of high blood cholesterol in adults (Adult Treatment Panel III) final report. Circulation 2002;106:3143-234.

6. McLean JW, Tomlinson JE, Kuang W-J, et al. CDNA sequence of human apolipoprotein(a) is homologous to plasminogen. Nature 1987;330:132-7.

http://dx.doi.org/10.1038/330132a0

7. Rajappa M, Sridhar MG, Balachander J, Sethuraman KR. Lipoprotein (a) and comprehensive lipid tetrad index as a marker for coronary artery disease in NIDDM patients in South India. Clin Chim Acta 2006;372:70-5. http://dx.doi.org/10.1016/j.cca.2006.03.019

8. Gouni-Berthold I, Berthold HK. Lipoprotein(a): current pers- 
pectives. Curr Vasc Pharmacol 2011;9:682-92. http://dx.doi.org/10.2174/157016111797484071

9. Tsimikas S, Witztum JL. The role of oxidized phospholipids in mediating lipoprotein(a) atherogenicity. Curr Opin Lipidol 2008;19:369-77. http://dx.doi.org/10.1097/MOL.0b013e328308b622

10. Ichikawa $T$, Unoki $H$, Sun $H$, et al. Lipoprotein(a) promotes smooth muscle cell proliferation and dedifferentiation in atherosclerotic lesions of human apo(a) transgenic rabbits. Am J Pathol 2002;160:227-36. http://dx.doi.org/10.1016/S0002-9440(10)64366-0

11. Kamstrup PR, Nordestgaard BG. Lipoprotein(a) should be taken much more seriously. Biomark Med 2009;3:439-41. http://dx.doi.org/10.2217/bmm.09.57

12. Rader DJ, Cain W, Zech LA, et al. Variation in lipoprotein(a) concentrations among individuals with the same apolipoprotein(a) isoform is determined by the rate of lipoprotein(a) production. J Clin Invest 1993;91:443-7. http://dx.doi.org/10.1172/JCl116221

13. Maher VM, Brown BG, Marcovina SM, et al. Effects of lowering elevated LDL cholesterol on the cardiovascular risk of lipoprotein(a). JAMA 1995;274:1771-4. http://dx.doi.org/10.1001/jama.1995.03530220037029

14. Bostom AG, Cupples LA, Jenner JL, et al. Elevated plasma lipoprotein(a) and premature coronary heart disease in men aged 55 years and younger. A prospective study. JAMA 1996;276:544-8. http://dx.doi.org/10.1001/jama.1996.03540070040028

15. Hopkins PN, Wu LL, Hunt SC, et al. Lipoprotein(a) interactions with lipid and nonlipid risk factors in early familial coronary artery disease. Arterioscler Thromb Vasc Biol 1997;17:2783-92. http://dx.doi.org/10.1161/01.ATV.17.11.2783

16. Hopkins PN, Hunt SC, Schreiner PJ, et al. Lipoprotein(a) interactions with lipid and non-lipid risk factors in patients with early onset coronary artery disease: results from the NHLBI Family Heart Study. Atherosclerosis 1998;141:333-45. http://dx.doi.org/10.1016/S0021-9150(98)00174-9

17. Boerwinkle E, Leffert CC, Lin J, et al. Apolipoprotein(a) gene accounts for greater than $90 \%$ of the variation in plasma lipoprotein(a) concentrations. J Clin Invest 1992;90:52-60. http://dx.doi.org/10.1172/JCl115855

18. Maeda S, Abe A, Seishima M, et al. Transient changes of serum lipoprotein(a) as an acute phase protein. Atherosclerosis 1989;78:145-50. http://dx.doi.org/10.1016/0021-9150(89)90218-9

19. Sorrentino MJ, Vielhauer C, Eisenbart JD, et al. Plasma lipoprotein (a) protein concentration and coronary artery disease in black patients compared with white patients. Am J Med 1992;93:658-62.

http://dx.doi.org/10.1016/0002-9343(92)90199-L

20. Brewer $\mathrm{H}$. Effectiveness of diet and drugs in the treatment of patients with elevated Lp(a) level. In Scanu A, editor: Lipoprotein(a). Orlando, Fl: Academic Press, 1990:211. http://dx.doi.org/10.1016/b978-0-12-620990-7.50018-8

21. Mbewu AD, Durrington PN. Lipoprotein(a): structure properties and possible involvement in thrombogenesis and atherogenesis. Atherosclerosis 1990;85:1-14. http://dx.doi.org/10.1016/0021-9150(90)90177-K

22. Nordestgaard BG, Chapman MJ, Ray K, et al. Lipoprotein(a) as a cardiovascular risk factor: current status. Eur Heart $J$ 2010;31:2844-53. http://dx.doi.org/10.1093/eurheartj/ehq386

23. Grundy SM, Cleeman JI, Merz CN, et al. Implications of recent clinical trials for the National Cholesterol Education
Program Adult Treatment Panel III guidelines. Circulation 2004;110:227-39.

http://dx.doi.org/10.1161/01.CIR.0000133317.49796.0E

24. Friedewald WT, Levy RI, Fredrickson DS. Estimation of the concentration of low-density lipoprotein cholesterol in plasma, without use of preparative ultracentrifugate. Clin Chem 1972;18:499-502.

25. Jauhiainen $M$, Koskinen P, Ehnholm C, et al. Lipoprotein(a) and coronary heart disease risk. A nested case-control study of the Helsinki Heart Study participants. Atherosclerosis 1991;89:59-67. http://dx.doi.org/10.1016/0021-9150(91)90007-P

26. Nascetti S, D'Addato S, Pascarelli N, et al. Cardiovascular disease and Lp(a) in the adult population and in the elderly: the Brisighella study. Riv Eur Sci Med Farmacol 1996;18:205-12.

27. Danesh J, Collins R, Peto R. Lipoprotein(a) and coronary heart disease. Meta-analysis of prospective studies. Circulation 2000;102:1082-5. http://dx.doi.org/10.1161/01.CIR.102.10.1082

28. Kamstrup PR, Tybjaerg-Hansen A, Steffensen R, Nordestgaard BG. Genetically elevated lipoprotein(a) and increased risk of myocardial infarction. JAMA 2009;301:2331-9. http://dx.doi.org/10.1001/jama.2009.801

29. Expert Panel on Detection, Evaluation, and Treatment of High Blood Cholesterol in Adults. Executive Summary of the Third Report of the National Cholesterol Education Program (NCEP) Expert Panel on Detection, Evaluation, and Treatment of High Blood Cholesterol in Adults (Adult Treatment Panel III). JAMA 2001;285:2486-97.

http://dx.doi.org/10.1001/jama.285.19.2486

30. Mellwig KP, Schatton C, Biermann B, et al. Lipoprotein(a): influence on cardiovascular manifestation. Clin Res Cardiol Suppl 2015;10:33-8. http://dx.doi.org/10.1007/s11789-015-0072-2

31. Emerging Risk Factors Collaboration, Erqou S, Kaptoge S, et al. Lipoprotein(a) concentration and the risk of coronary heart disease, stroke, and nonvascular mortality. JAMA 2009;302:412-23. http://dx.doi.org/10.1001/jama.2009.1063

32. Marcovina SM, Koschinsky ML, Albers JJ, Skarlatos S. Report of the National Heart, Lung, and Blood Institute Workshop on lipoprotein(a) and cardiovascular disease: recent advances and future directions. Clin Chem 2003;49:1785-96. http://dx.doi.org/10.1373/clinchem.2003.023689

33. Sharrett AR, Ballantyne CM, Coady SA, et al. Coronary heart disease prediction from lipoprotein cholesterol levels, triglycerides, lipoprotein(a), apolipoproteins A-I and B, and HDL density subfractions: the Atherosclerosis Risk in Communities (ARIC) Study. Circulation 2001;104:1108-13. http://dx.doi.org/10.1161/hc3501.095214

34. Craig WY, Neveux LM, Palomaki GE, et al. Lipoprotein(a) as a risk factor for ischemic heart disease: metaanalysis of prospective studies. Clin Chem 1998;44:2301-6.

35. Wu HD, Berglund L, Dimayuga C, et al. High lipoprotein(a) levels and small apolipoprotein(a) sizes are associated with endothelial dysfunction in a multiethnic cohort. J Am Coll Cardiol 2004;43:1828-33. http://dx.doi.org/10.1016/j.jacc.2003.08.066

36. Paultre F, Pearson TA, Weil HFC, et al. High levels of $L p(a)$ with a small apo(a) isoform are associated with coronary artery disease in African American and white men. Arterioscler Thromb Vasc Biol 2000;20:2619-24. http://dx.doi.org/10.1161/01.ATV.20.12.2619 